\title{
Dyeability of Nanofibers with Reactive, Vat and Disperse Dyes
}

\author{
Farooq Ahmed, Umair Ahmed Qureshi, and Zeeshan Khatri
}

\begin{abstract}
Colorful nanofibers were prepared through electrospinning technique followed by dyeing with different reactive dyes by comparing different dyeing techniques such as ultrasonic as well as conventional (padding method). Excellent color yield and color fastness were achieved through proper optimization conditions in ultrasonic treatment. Nanofibers exhibited smooth and bead free morphology. Two different polymers were selected for electrospinning, i.e. cellulose acetate and nylon-6. Preparation of cellulose nanofibers included electrospinning of cellulose acetate following deacetylation under alkaline conditions. Results suggested that dyes conferred improved color yield on the basis of $K / S$ values. Deacetylation was also confirmed through FTIR. The resulting nanofibers can serve better choice for advanced apparel applications.
\end{abstract}

Index Terms-Padding, batch wise, dyed nanofibers.

\section{INTRODUCTION}

Nanofibers are drawing intense research interests because of ease of fabrication and wide variety of polymers used for electrospinning. They find wide variety of applications such as filters [1], biosensors [2], [3], wound healing [4], tissue scaffolds [5], drug delivery [6], [7], breathable membranes [8], [9] and nanocomposites [10]. Nanofibers are also considered as excellent water absorbents and offer greater flux for water vapors [11]. Different waterproof breathable nanofibers are reported [12]-[14]. Literature survey reveals broad application of nanofibers for apparel use but colorimetric properties are rarely discussed. The fundamental technique for production of colored nanofibers is to dye the nanofiber sample after electrospinning and color yield is the main criterion in selecting best quality of nanofiber. Therefore, present research focuses on the production of colored nanofibers after post electrospinning treatment through different techniques such as conventional as well as ultrasonic. In present work we have prepared two types of nanofibers, i.e. cellulose nanofibers and nylon-6 nanofibers followed by dyeing with reactive dyes and vat dyes. The dyeing procedure was compared through two techniques, i.e., conventional method and ultrasound assisted method. Different parameters such as color yield $(\mathrm{K} / \mathrm{S})$, color fastness to light and washing tests were assessed for dyed nanofibers. The characterization of resulting nanofibers was obtained by analytical techniques such as scanning electron microscopy (SEM) and FTIR.

Manuscript received November 9, 2018; revised January 25, 2019.

The authors are with Centre of Excellence in Nanotechnology and Materials, Mehran University of Engineering and Technology, Jamshoro, Pakistan (e-mail: farooq.ahmed@faculty.muet.edu.pk, ahmedumair2011@gmail.com, zeeshan.khatri@faculty.muet.edu.pk).

\section{EXPERIMENTAL}

\section{A. Materials}

Following reagents were used in present work: Cellulose acetate (CA) and Nylon 6 (Sigma-Aldrich USA) . CI reactive black 5 (RB 5), CI disperse blue 167:1 (DB 167:1) and (Sumitomo, Japan, Archroma, Pakistan and Huntsman, USA respectively). The chemical structures of studied dyes are given in Fig. 1.
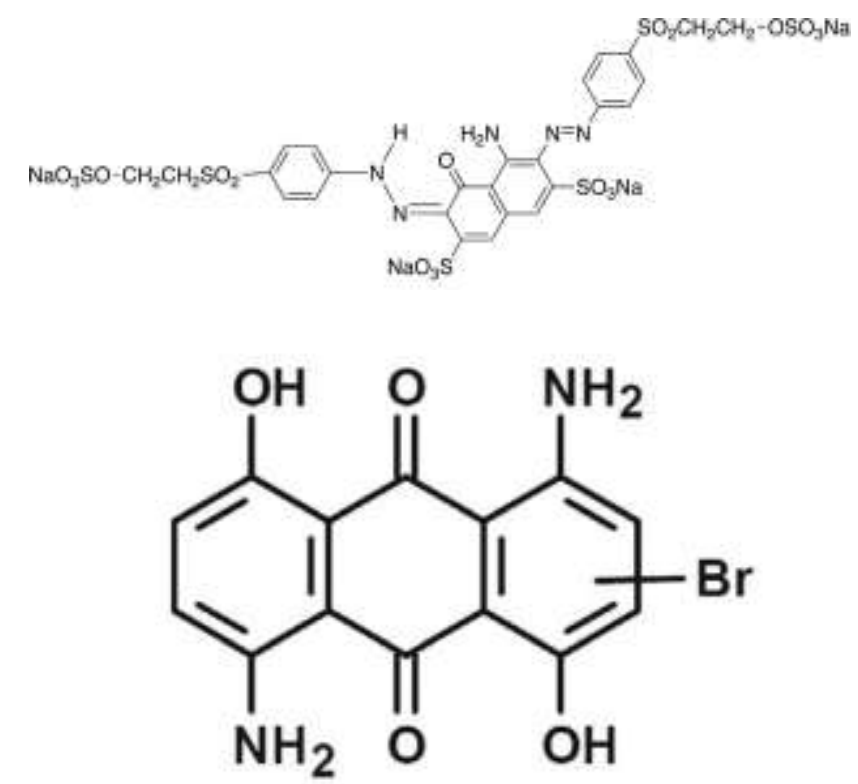

Fig. 1. Chemical structures of reactive black (RB 5) and disperse blue 167:1 (DB 167:1).

\section{B. Nanofiber Preparation and Dyeing Experiment}

Polymer solutions for cellulose and nylon- 6 were prepared by previously reported methods [15], [16]. Concisely, different polymer solutions were poured in syringes and voltages (around 10-15 kV) were applied to produce fine and thin nanofibers. Rotating metallic drum was used for the collection of electrospun nanofibers until the required thickness of web reached $40-60 \mu \mathrm{m}$.

Padding method was used for dyeing of CA nanofibers whereas; batch wise method was adapted for dyeing CNFs and nylon nanofibers. Briefly, padding of CA nanofibers using dye liquor at $65 \%$ pickup was carried out followed by drying at $120^{\circ} \mathrm{C}$ and curing at $180^{\circ} \mathrm{C}$ for 2 minutes. Liquor to good ratio of 50:1 was used in batch wise dyeing for CNFs at $60{ }^{\circ} \mathrm{C}$ for $30 \mathrm{~min}$. In order to ultrasonicate nanofibers, sonication frequency was selected at $40 \mathrm{kHz}$. Samples were measured by K/S values, color fastness to light and washing. The morphologies of nanofibers before and after dyeing were analyzed by SEM. 


\section{RESUlTS AND DisCUSSION}

Two different methods, i.e., conventional and ultrasonic methods were used for dyeing of nanofibers. UV Vis Spectrosphotometer was used for measuring color yield values.
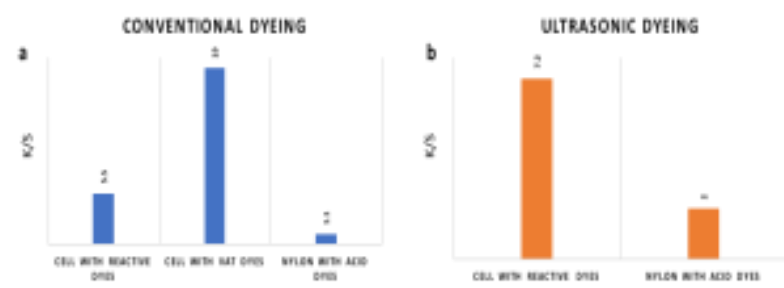

Fig. 2. Comparison of dyeing with (a) conventional and (b) US method.

\section{A. Conventional Dyeing}

From the Fig. 2(a), it is clear that cellulose nanofibers dyed with reactive dyes showed color yield of 5.5. The K/S values of cellulose nanofibers when dyed with vat dyes was 19 that is 3 times greater than former. The possible reason behind this can be higher molar extinction coefficient of vat dye than reactive. On the other hand, low K/S values were noticed with disperse dyes dyed on nylon- 6 nanofibers owing to greater crystalline domain that inhibit their diffusion.

\section{B. Ultrasonic Dyeing}

Fig. 2(b) presents ultrasonically treated nanofibers using reactive and vat dyes. Contrary to reactive dyes, vat dye showed improved K/S value (7.2) on cellulose nanofibers. This may be due to ultrasonic cavitation generated due to sonication. Ultrasonically dyed nylon-6 nanofibers also showed greater K/S values (2) that was also better than conventional method.

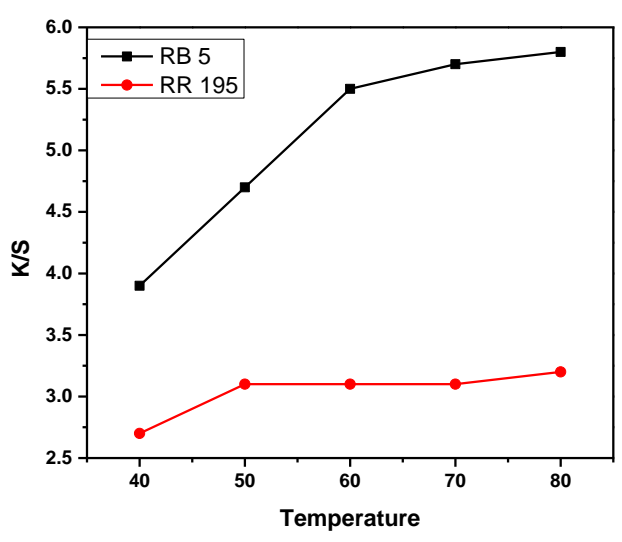

Fig. 3. Effect of dyeing temperature on color yield.

\section{Effect of Temperature on Dyeing of Nanofibers.}

As ultrasonic dyeing is reported for the very first time, therefore it was necessary to optimize dyeing parameter such as temperature. To begin with this, temperature was optimized using cellulose nanofibers at fixed time i.e. $80 \mathrm{~min}$ using C.I RB 5 and C.I RR 195. The color yield using RB\% increased steeply from $40^{\circ} \mathrm{C}$ to $60^{\circ} \mathrm{C}$ that became constant on further rise in temperature as shown in Fig. 3. This could be due to substantivity ratio and hydrolysis of dye molecules on extremely higher temperatures. Irrespective to the dyeing temperature, the color yield of $\mathrm{CI}$ reactive black 5 obtained higher than the CI reactive red 195 . This may be due to the difference of molar extinction coefficient, affinity and reactivity between both dyes. On the other hand, dye uptake of CI reactive red 195 slowly increased from $40{ }^{\circ} \mathrm{C}$ to $60{ }^{\circ} \mathrm{C}$ and reached higher yield at $70{ }^{\circ} \mathrm{C}$. This steady profile of $\mathrm{CI}$ reactive red 195 is due to lowering of substantivity ratio caused by increasing temperature. Whereas, for nylon nanofibers using disperse dyes the dyeing at fixed time (60 $\mathrm{min}$ ), the maximum color yield obtained was at $80 \mathrm{C}$ beyond which the K/S values decreased due to either dye hydrolysis or migration of dye molecules back to solution phase from nanofiber phase.

\section{Effect of Dyeing Time on Color Yield}

Considering maximum dye uptake by cellulose nanofibers at $70{ }^{\circ} \mathrm{C}$ using $\mathrm{RB} 5$, impact of dyeing time on ultrasonic dyeing on cellulose nanofibers was investigated. RB5 shows steep rise in dye uptake with increase in time from $10 \mathrm{~min}$ to $20 \mathrm{~min}$, further increase in time did not affect dye uptake and rendered a plateau beyond $20 \mathrm{~min}$ in the graph. This may be attributed to ultrasonic cavitation that breaks dye aggregates and tends to increase dye uptake. On the basis of these results $30 \mathrm{~min}$ were selected optimum for RB5 dyeing using cellulose nanofibers. Nylon-6 nanofibers also show similar behavior while using disperse dyeing. Whereas conventional dyeing rendered modest dye uptake and reached its maximum capacity at $60 \mathrm{~min}$ shown in Fig. 4. It is further suggested that sonication promotes significant mass transfer and transient cavitation near fiber surface are responsible for improved results.

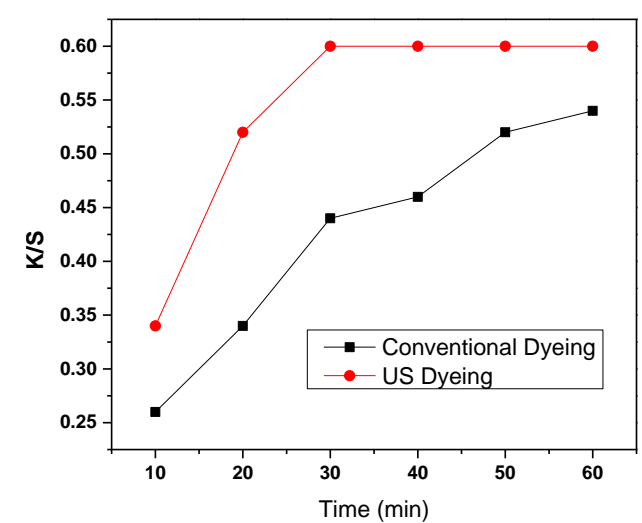

Fig. 4. Effect of dyeing time on color yield.

\section{E. Color Fastness}

Table I summarizes the the results of color fastness to light and washing. ultrasonically treated dyes showed better light fastness tests (4) compared to conventional. Vat dyes had better light fastness (7). This improvement on light fastness can be due to bulkier molecule size of vat dyes than the reactive. The observed light fastness in case of nylon 6 nanofibers was only 2 regardless of the dyeing technique. Generally, washing fastness of nanofibers was extremely excellent in performance. For instance, shade change of cellulose nanofiber was $3 / 4$ and 4 with reactive dyes, however, vat dye showed $4 / 5$ better than the later. However, except cellulose nanofibers, the staining was $4 / 5$ to 5 with other samples. Cellulose nanofibers dyed with reactive dyes presented staining 3 only. Sonication obviously does not 
influence color fastness of the nanofibers. Color fastness to hot pressing was evaluated for each dyed nanofibers, the shade change and staining ratings obtained $4 / 5$ for nanofibers dyed with CI Disperse Red 167:1. The nanofibers dyed by ultrasonic method did not show any difference than the nanofibers dyed by conventional method. Since the CI Disperse Red 167:1 is high energy level dye, it showed better fastness (hot pressing) results

TABLE I: COMPARISON OF LIGHT FASTNESS AND WASHING FASTNESS

\begin{tabular}{|c|c|c|c|c|}
\hline \multicolumn{5}{|c|}{ TESTS } \\
\hline Nanofiber & Dye & Light & $\begin{array}{l}\text { Washing, } \\
\text { Sh. Ch. }\end{array}$ & $\begin{array}{l}\text { Washing } \\
\text { Co. } \\
\text { staining }\end{array}$ \\
\hline $\begin{array}{l}\text { Cell. } \\
\text { nanofibers }\end{array}$ & RB5 & 3 & $3 / 4$ & 3 \\
\hline $\begin{array}{l}\text { US-Cell. } \\
\text { nanofibers }\end{array}$ & RB5 & 4 & 4 & 5 \\
\hline $\begin{array}{l}\text { Cell. } \\
\text { nanofibers }\end{array}$ & Vat-Blue 4 & 7 & $4 / 5$ & $4 / 5$ \\
\hline $\begin{array}{l}\text { Nylon } 6 \\
\text { nanofibers }\end{array}$ & DR167:1 & 2 & $3 / 4$ & $4 / 5$ \\
\hline $\begin{array}{l}\text { US-Nylon } \\
6 \\
\text { nanofibers }\end{array}$ & DR 167:1 & 2 & $3 / 4$ & $4 / 5$ \\
\hline
\end{tabular}

\section{F. Nanofibers Morphology}

Fig. 5 reveals SEM images of dyed cellulose and nylon nanofibers. All nanofibers were smooth and bead free in morphlogy. It can also be observed that the diameter of cellulose nanofibers was greater $(400 \mathrm{~nm}$ to $600 \mathrm{~nm})$ than nylon-6 (80-150 nm. Dyeing procedure had no detrimental impact on nanofibers morphology. However, ultrasonic treatment caused a little detrimental impact.

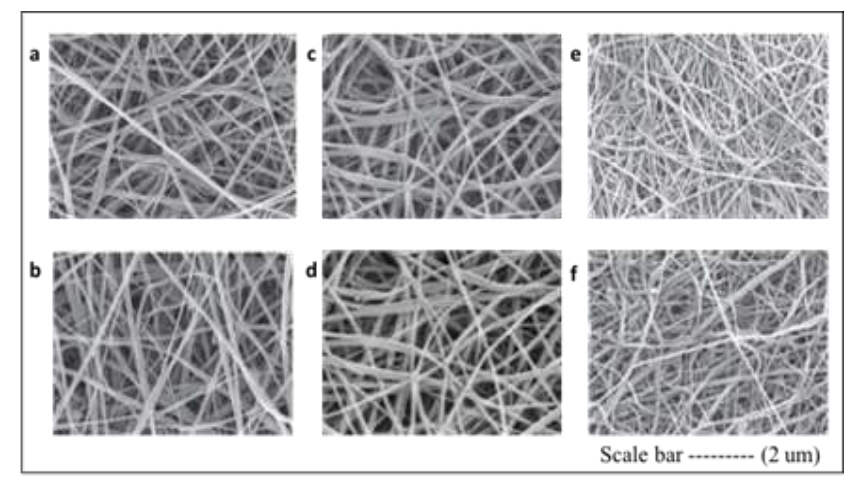

Fig. 5. SEM images of cellulose nanofibers (a) through conventional dyeing with reactive dye (b) through ultrasonic treatment (c) without dye cellulose nanofibers (d) Nylon-6 nanofibers convetionally dyed with vat dyes (e) conventional treatment of disperse dye(f) Ultrasonic treatment of nylon-6 nanofibers.

\section{A. FTIR Characterization}

The successful conversion of CA nanofibers into CNFs and subsequent dyeing was confirmed through FTIR as shown in Fig. 6. The disappearance of characteristic peaks from cellulose acetate i.e. 1745 due to $\mathrm{C}=\mathrm{O}, 1375$ due to $\mathrm{C}-\mathrm{CH} 3,1235$ due to $\mathrm{C}-\mathrm{O}-\mathrm{C}$ confirms the successful conversion of cellulose acetate to cellulose. However, there was no significant change in the IR absorption bands of cellulose before and after dyeing that implies that ultrasonic treatment has no influence on chemical structure of cellulose.

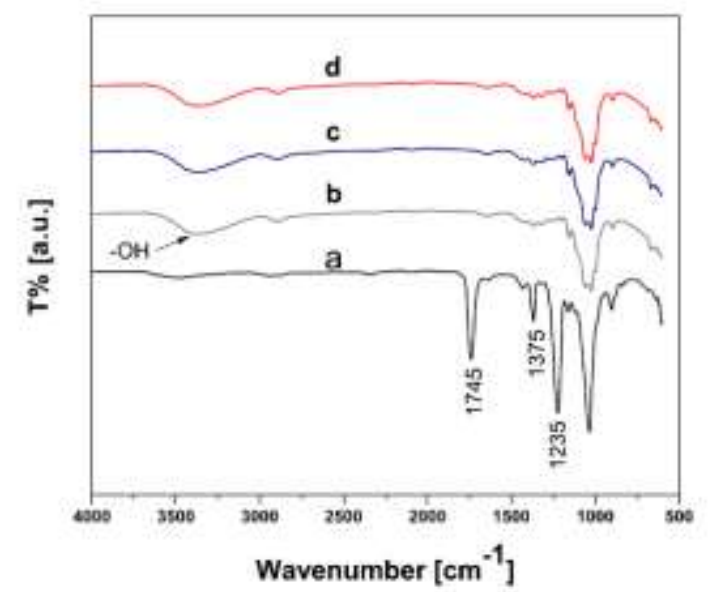

Fig. 6. FTIR analysis of (a) CA nanofibers, (b) CNFs (c) CNF dyed with RB 5 and (d) RR 195

\section{B. Mechanical Study of Nanofibers}

Fig. 7 shows comparison of tensile strength between US dyed nylon-6 nanofibers and conventionally dyed nanofibers. Since cellulose nanofibers were not in condition and lost their strength after US dyeing, therefore, nylon- 6 nanofibers were considered suitable for measuring mechanical properties. Nylon-6 nanofibers dyed with US technique showed a substantial improvement in mechanical strength (3 to $3.5 \mathrm{~N}$ tensile strength) in contrast to the conventional dyeing. The probable reason behind this can be cavitation during ultrasonic dyeing that imparted stiffness to the nylon- 6 nanofibers. To confirm the influence of dye class on mechanical strength of nylon-6 nanofibers the nanofibers were subjected to US in water referred as blank. It was observed that dyeing class had no impact in imparting mechanical strength. Their greater stiffness and tensile strength can trigger its applications as surgical apparel.

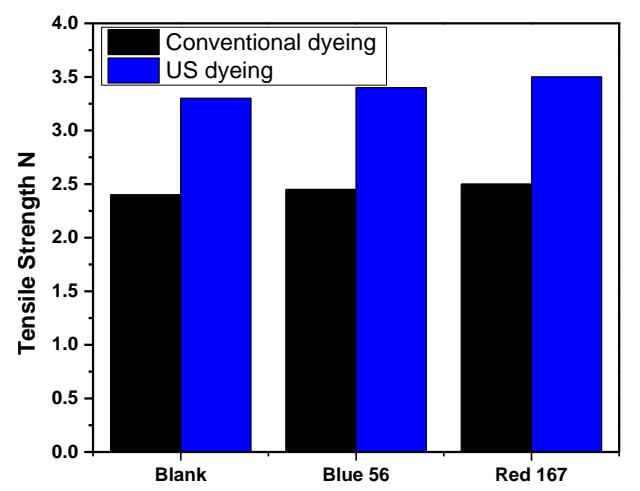

Fig. 7. Comparison of tensile strength of nylon- 6 nanofibers dyed through US and conventional method.

\section{CONCLUSION}

Cellulose and nylon-6 nanofibers were successfully prepared and dyed using different dyes. Excellent color yield was obtained using cellulose nanofibers than nylon-6. US dyeing of nanofibers showed better color yield than conventional dyeing. US dyeing completes within at $30 \mathrm{~min}$, which is half of the conventional dyeing, which demonstrates substantial time reduction. Irrespective to the dye class used, the US dyeing showed a significant increase in $\% \mathrm{~F}$ as compared to conventional dyeing, however, the $\% \mathrm{~F}$ 
decreased upon dye concentration increased. Dyeing of nylon-6 nanofibers with conventional method showed low $\mathrm{K} / \mathrm{S}$ values, however similar dyeing with ultrasonic method improved its color yield. SEM images confirmed smooth and beadles nanofibers. On the basis of the color fastness and light fastness tests, it can be suggested that nanofibers can be effectively used for apparel applications. Color fastness tests indicate good dye fixation based on good to very good rating in color fastness to washing and hot pressing. The nanofibers dyed with US dyeing method showed a significant increase of tensile strength in comparison to conventional dyeing method.

\section{ACKNOWLEDGMENT}

The authors are grateful to Mehran University of Engineering and Technology Jamshoro Pakistan for providing lab and chemicals. The authors also pay gratitude to Prof. Ick Soo Kim from Shinshu University Japan for providing characterization facilities

\section{REFERENCES}

[1] N. Daels, S. D Vrieze, I. Sampers, B. Decostere, P. Westbroek, A. Dumoulin, P. Dejans, K. De Clerck and S. W. H. Van-Hulle, "Potential of a functionalised nanofibre microfiltration membrane as an antibacterial water filter," Desalination, vol. 275, p. 285, 2011.

[2] J. S. Huang, Y. Liu, and T. You, "Carbon nanofiber based electrochemical biosensors: A review," Anal. Methods, vol. 2, p. 202, 2010.

[3] X. Lu, J. Zhou, W. Lu, Q. Liu, and J. Li, "Carbon nanofiber-based composites for the construction of mediator-free biosensors," Biosens. Bioelectron., vol. 23, pp. 1236-1243, 2008.

[4] M. S. Khil, D. I. Cha, H. Y. Kim, I. S. Kim, N. Bhattarai, and J. Biomed, "Electrospun nanofibrous polyurethane membrane as wound dressing" Mater Res. Part B: Appl. Biomater., vol. 67, pp. 675-679, 2003.

[5] C. S. Ki, J. W Kim, J. H. Hyun, K. H .Lee, M. Hattori, D. K. Rah, and Y. H. Park, "Dissolution and wet spinning of silk fibroin using phosphoric acid/formic acid mixture solvent system," J. Appl. Polym. Sci., vol. 106 p. 3922, 2007.

[6] H. S. Yoo, T. G. Kim, and T. G. Park, "Surface-functionalized electrospun nanofibers for tissue engineering and drug delivery," Adv. Drug Deliv. Rev., vol. 61, pp. 1033-1042, 2009.

[7] Y. K. Luu, K. Kim, B. S. Hsiao, B. Chu, and M. Hadjiargyrou, "Development of a nanostructured DNA delivery scaffold via electrospinning of PLGA and PLA-PEG block copolymers," $J$. Control. Release, vol. 89, pp. 341-353, 2003.

[8] P. Gibson, H. Schreuder-Gibson, and D. Rivin, "Transport properties of porous membranes based on electrospun nanofibers," Colloids Surf. A, vol. 187-188, pp. 469-481, 2001.

[9] M. Gorji, A. A. Jeddi, and A. A. Gharehaghaji, "Fabrication and characterization of polyurethane electrospun nanofiber membranes for protective clothing applications," J. Appl. Polym. Sci., vol. 125, p. 4135 , 2012.

[10] C. Wang, Y. Li, G Ding, X. Xie, and M. Jiang, "Synthesis of polyimide oligomer attached with hemicyanine dye," J. Appl. Polym. Sci..

[11] L. Sumin, D. Kimura, A. Yokoyama, K. H. Lee, J. C. Park, and I. S. Kim, Text. Res. J., vol. 79, p. 1085, 2009.
[12] B. Yoon and S. Lee, "Designing waterproof breathable materials based on electrospun nanofibers and assessing the performance characteristics," Fibers Polym., vol. 12, p. 57, 2011.

[13] A. A. Babar, X. Wang, N. Iqbal, J. Yu, and B. Ding, "Tailoring Differential Moisture Transfer Performance of Nonwoven/Polyacrylonitrile-SiO $\backslash \mathrm{r} \quad 2 \backslash \mathrm{r} \quad$ Nanofiber Composite Membranes," Adv. Mat. Inter., vol. 4, 2017.

[14] J. Ju, Z. Shi, N. Deng, Y. Liang, W. Kang, and B. Cheng, "Designing waterproof breathable material with moisture unidirectional transport characteristics based on a TPU/TBAC tree-like and TPU nanofiber double-layer membrane fabricated by electrospinning," RSC $A d v$., vol. 7, p. 32155, 2017

[15] F. Ahmed, A. A Arbab, A. W Jatoi, M. Khatri, N. Memon, Z. Khatri, and I. S. Kim, Ultrasonic-assisted deacetylation of cellulose acetate nanofibers: A rapid method to produce cellulose nanofibers," Ultrason Sonochem., vol. 36, pp. 319-325, 2017.

[16] A. W. Jatoi, F. Ahmed, M. Khatri, A. Tanwari, Z. Khatri, H. Lee, and I. S. Kim, "Ultrasonic-assisted dyeing of Nylon-6 nanofibers," Ultrason Sonochem, vol. 39, pp. 34-38, 2017.

Farooq Ahmed is currently serving as a professor in Textile Engineering Department, Mehran University of Engineering and Technology. He obtained his B.Sc in engineering from National Textile University, Faislabad, Pakistan in the year 1996 and secured doctorate degree in textile Engineering from Mehran University of Engineering and Technology, Jamshoro Pakistan in the year 2013. He joined Mehran University in the year 1998. His research interests include nanofibers, nanomateriala, environmental concerns regarding textile, Textile testing and quality control. He has published more than 25 publications in SCI-SCI expanded Journals.

Umair Ahmed Qureshi is a lecturer in chemistry at Government Boys Degree College Qasimabad Hyderabad, Pakistan. He is doing post doctorate research in Centre of Excellence in Nanotechnology and Materials Mehran University of Engineering and Technology Jamshoro Pakistan. He obtained his BS degree in organic chemistry in the year 2008 from University of Sindh Jamshoro Pakistan and obtained PhD in analytical chemistry in 2015 from same University. He was also awarded split $\mathrm{PhD}$ scholarship sponsored by scientific and technological research council of Turkey in the year 2013-2014. His research interests include nanofibers, electrospinning, environmental analytical chemistry, chromatographic separations and determinations of endocrine disrupting compounds.

Zeeshan Khatri is a professor at Department of Textile Engineering, Mehran University Jamshoro. He started his professional career in the yea 2000 after graduating from (94 batch) Mehran University Jamshoro. He has 17 years academic and industrial experience. After spending 8 years in textile industry, he joined Mehran University as a lecturer in the year 2009 and did his ME in textile engineering. He then pursued for doctorate degree and completed within 2.5 years from Shinshu University Japan in September 2013. He also owns professional titles CCol ASDC (UK) and CText ATI (UK) and PE (Pak). In 2004, SDC awarded him a President's Diploma of Honor on his most meritorious performance in ASDC examinations

Dr. Khatri is a principal investigator of Nanomaterial Research Group, comprising of eminent scientist around globe. He has 38 international publications with cumulative impact factor of 130.0 and 2 book chapters published by Springer. Dr. Khatri has been a national speaker at various conferences, seminars and workshops and participated more than 100 national and international conferences. Dr. Khatri is a lead guest editor of annual issue in Journal of Nanomaterials (impact factor 1.7). He is inventor of various nanofibers membranes, on his credit are 2 Japanese patent, 1 US Patent and 6 patents have been filed. Dr. Khatri is a co-founder of nano CLO and CEO of MuTech (Pvt) Ltd 